\title{
Experiments on the combined use of a double-sided pressure-sensitive tape and an epoxy adhesive to reduce handling time
}

\author{
A. Bernasconi, S. Cardamone, M. Giglio \\ Dipartimento di Meccanica, Politecnico di Milano, Milan, Italy
}

Via G. La Masa 1, 20156 Milan, Italy. Email: andrea.bernasconi@polimi.it

\begin{abstract}
In many industrial assemblies with structural adhesives, the handling time, i.e. the time to safely move adhesively bonded parts, may slow down manufacturing process and result into additional costs. For that reason, in some cases, the traditional mechanical connections (rivets, bolts, welds) are still preferable when the structure must be completed in a short time. In this work a new type of hybrid joint, characterized by the combined use of an epoxy adhesive and a double-sided pressure-sensitive tape, is proposed and characterized by experimental tests on single-lap joints with a large overlap. The results showed that these hybrid joints allow for reducing the handling time of the joint, preserving approximately the same strength. The proposed solution exploits the nonuniform stress distribution in the bondline of a singlelap joint, resulting in a low stress area at the centre of the overlap. The presence of an adhesive tape in this region does not affect the strength of the joint, while provides the joint with sufficient strength for being handled before the full cure of the epoxy.
\end{abstract}

Keywords: hybrid joint; epoxy/epoxides; pressure-sensitive; tape; single lap; lap shear. 


\section{Introduction}

Adhesive bonding is one of the most innovative mechanical joining technique, particularly suitable for lightweight design. In various industrial fields, such as automotive, aerospace and renewable industry, saving weight is crucial for cost reduction and economic feasibility of new concept of structures. Compared to traditional mechanical joints, the use of adhesive generally means a simplification of shape and geometry of the joint, with a great reduction of weight, while preserving or even increasing the stiffness. Adhesive bonding is also useful for avoiding hole drilling operations (as required by bolts and rivets) and does not induce changes in the microstructure of the parts to be joined (as it may happen with welding) [1-2].

To substitute a traditional mechanical joint with an adhesively bonded one means, in most cases, re-designing the structure and taking into account specific issues related to the chemical nature of adhesive joints. One of the most critical aspects is the handling time of the adhesive, i.e. the time to wait before handling the joint or continuing the assembly of an adhesively bonded structure. The handling time is a part of the curing time, i.e. the time of polymerisation. A two-part epoxy adhesive begins to cure when the two components (epoxy resin and hardener) are mixed together and the reaction starts [1]. The length of the curing time, and consequently of the handling time, can be controlled by adding chemical additives and it is a function of the temperature of the environment (fast cure is generally achieved at high temperatures). Nevertheless, in many cases the open time is deliberately kept long to leave enough time, during the assembly operations, to join long parts with good alignment precision, to perform quality inspection before moving to another assembly step, and to re-position the parts in case of errors in the assembly operations. Consequently, the handling time is postponed and this may slow down the assembly process, usually resulting into additional costs. 
This paper presents an experimental investigation on a possible solution proposed to overcome the disadvantage of long handling and curing times by means of the combination of a structural adhesive and a double-sided pressure-sensitive tape. This hybrid joint configuration has the potential of almost cancelling the handling time, since pressure-sensitive tapes, placed near a layer of structural adhesive not yet solidified, provide an almost instantaneous handling strength and they allow to immediately continue to assemble the bonded component with other parts. After the curing time, the structural adhesive will provide most of the strength of the joint.

Various pressure-sensitive tapes have been studied in the literature under different conditions and loads [3-6]. They usually provide lower strength than most of the structural adhesives, but they are very fast to be applied because it takes just an instantaneous pressure to activate them. Various hybrid joints have been characterized in the literature and used for industrial applications [7], like adhesive in combination with rivets [8-9], spot welding [10-11], and other type of adhesives [12]. The combination of pressuresensitive tapes and mechanical joints has been evaluated with T-peel joints [13]. In the present paper, the mechanical characterization of hybrid joints, combining the technology of structural adhesives with pressure-sensitive tapes, was performed by means of nonstandard (i.e. having an overlap length different from that suggested by the test standards) Single-Lap Joints (SLJ).

In the literature, SLJs with overlap of different length were used by Saldanha et al. [14], who adopted overlaps from 12.5 to $50 \mathrm{~mm}$ to characterize a high toughness epoxy adhesive. They observed an increase of the strength with larger overlaps (for high strength steel adherends) or an increase of yield and elongation of the adherend (for a mild steel). The effect of the presence of a gap in the bondline of SLJs was studied in the literature, 
beginning with the work of Olias and Rossettos [15], where it was demonstrated that peak stresses in SLJs with a central gap are unaffected far from the void, while, if the gap is sufficiently close to the end of the overlap, peak stresses can be affected only up to $25 \%$. Furthermore, experimental tests and numerical analyses were made for this type of joint by Lang and Mallick [16], considering the gap as a recessed bonding, and by de Moura et al. considering it as a strip defect [17]. In both cases, it was verified that the strength of the joints is not affected by the size of the defect, at least within a certain limit. Finally, the relationship between the ultimate shear stress, failure strength and the gap size in SLJ was studied by Engerer and Sancaktar [18] for two different (highly deformable and brittle) adhesives for steel substrates with and without end taper.

The aforementioned papers demonstrate that the presence of a gap in the bondline does not affect significantly the strength of a SLJ. Therefore, in this paper a preliminary investigation was conducted on the possibility of filling this gap in the bondline of a SLJ with a pressure sensitive tape to achieve an almost instantaneous handling strength, without affecting the strength of the joint.

\section{Experimental}

The structural adhesive chosen for the experimental campaign was the 3M ScotchWeld ${ }^{\mathrm{TM}} 7260$ B/A NS, a two-component epoxy adhesive [19]. This adhesive has a considerable strength (Table 1 lists the main mechanical properties) and a relatively long open time $\left(>300 \mathrm{~min}\right.$ at $\left.23^{\circ} \mathrm{C}\right)$. This last aspect makes it particularly suitable for the assembly of large structures. However, handling time and full curing time at room temperature may exceed 18 hours and 3 day, respectively [20]. In order to reduce these times, curing at temperature higher than ambient temperature is often suggested, e.g. for 
the present adhesive a $60-65^{\circ} \mathrm{C}$ proposed curing cycle results into a 180 -min curing time [19]. However, this may not be possible in the case of large structures that cannot be oven cured and consequently curing at room temperature is unavoidable.

Table 1. Mechanical properties of the 3M 7260 B/A NS adhesive [19]

\begin{tabular}{|c|c|c|c|}
\hline Property & Value & Test conditions & Standard \\
\hline \multirow[t]{2}{*}{$\begin{array}{l}\text { Overlap Shear Strength } \\
(\mathrm{MPa})\end{array}$} & 35.5 & $\begin{array}{c}\text { Test temperature: } 23^{\circ} \mathrm{C} \\
\text { Curing: } 24 \text { hours at } 35 \pm 2{ }^{\circ} \mathrm{C} \\
\text { under a pressure of } 100 \mathrm{kPa} \\
\text { Substrate: } 1.6 \mathrm{~mm} \text { thick } 2024 \\
\text { T3 clad aluminium, surface } \\
\text { prepared } \\
\text { using the optimised FPL etch }\end{array}$ & EN 2243-1 \\
\hline & 35 & $\begin{array}{c}\text { Test temperature: } 23^{\circ} \mathrm{C} \\
\text { Curing: } 24 \text { hours at } 35 \pm 2{ }^{\circ} \mathrm{C} \\
\text { under a pressure of } 100 \mathrm{kPa} \\
\text { Substrate: Hot dip galvanised } \\
\text { steel }\end{array}$ & EN 2243-1 \\
\hline $\begin{array}{l}\text { Thick Adherend Shear } \\
\text { strength }(\mathrm{MPa})\end{array}$ & 40.5 & $\begin{array}{c}\text { Test temperature: } 23^{\circ} \mathrm{C} \\
\text { Curing: } 24 \text { hours at } 35 \\
\pm 3^{\circ} \mathrm{C} \text { under a pressure of } 100 \\
\mathrm{kPa} \\
\text { Substrate: } 6 \mathrm{~mm} \text { thick } \\
2024 \mathrm{~T} 3 \text { aluminium, surface } \\
\text { treated by the optimised FPL } \\
\text { etch }\end{array}$ & EN 2243-6 \\
\hline
\end{tabular}

The double-sided pressure-sensitive tape chosen for working in combination with the epoxy adhesive was the $3 \mathrm{M} \mathrm{VHB}^{\mathrm{TM}} 5908$ Tape [21]. The tape has a width of $25 \mathrm{~mm}$ and a thickness of $250 \mu \mathrm{m}$. It is a modified acrylic adhesive, with a highly conformable acrylic foam core. Mechanical properties are reported in Table 2. 
Table 2. Mechanical properties of the 3N VHB 5908 Tape [21]

\begin{tabular}{c|c|c|c}
\hline Property & Value & Test conditions & Standard \\
\hline $90^{\circ}$ Peel adhesion $(\mathrm{N} / \mathrm{cm})$ & 21 & $\begin{array}{c}\text { On stainless steel } \\
\text { Room temperature }\end{array}$ & ASTM D3330 \\
\hline Normal tensile $(\mathrm{kPa})$ & 690 & $\begin{array}{c}\text { To Aluminium } \\
\text { Room temperature }\end{array}$ & ASTM D-897 \\
\hline Static shear $(\mathrm{MPa})$ & 0.03 & $\begin{array}{c}\text { On stainless steel } \\
\text { Test temperature: } 22^{\circ} \mathrm{C} \\
\text { Will hold for } 10,000 \mathrm{~min}\end{array}$ & ASTM D3654 \\
\hline
\end{tabular}

The experiments consisted in a series of shear-lap tests with different types of SLJ. The shear-lap is one of the most used tests for its simplicity and the possibility to compare different adhesives. The overlap length of a standard SLJ is $12.5 \mathrm{~mm}$ [22]. Due to the difficulty of manually cutting and placing a narrow strip of tape over the short overlap of a standardized SLJ, a $50 \mathrm{~mm}$ overlap was chosen for this campaign. Figure 1 shows the difference between a standardized SLJ and the specimen chosen for this work.

Three main types of specimens were designed and manufactured, identified with the letters A, B and C, as shown in Figure 1. The A specimen is a simple SLJ and it has an overlap of $50 \mathrm{~mm}$, which is completely filled by adhesive. This type of specimen has been tested for comparison with the following two types. The B specimen has the same overlap as the previous one, but with a gap (void) of $25 \mathrm{~mm}$ in the middle of the adhesive layer. This space, not filled by the adhesive, was controlled using an insert of polytetrafluoroethylene (PTFE) $0.1 \mathrm{~mm}$ thick tape. The $\mathrm{C}$ specimen, which had never been studied so far in the SLJ configuration, is the hybrid joint that combines epoxy adhesive and pressure-sensitive tape. In the $\mathrm{C}$ specimen, the same gap of the B specimen has been filled by a $25 \mathrm{~mm}$ wide double-sided pressure-sensitive tape. 

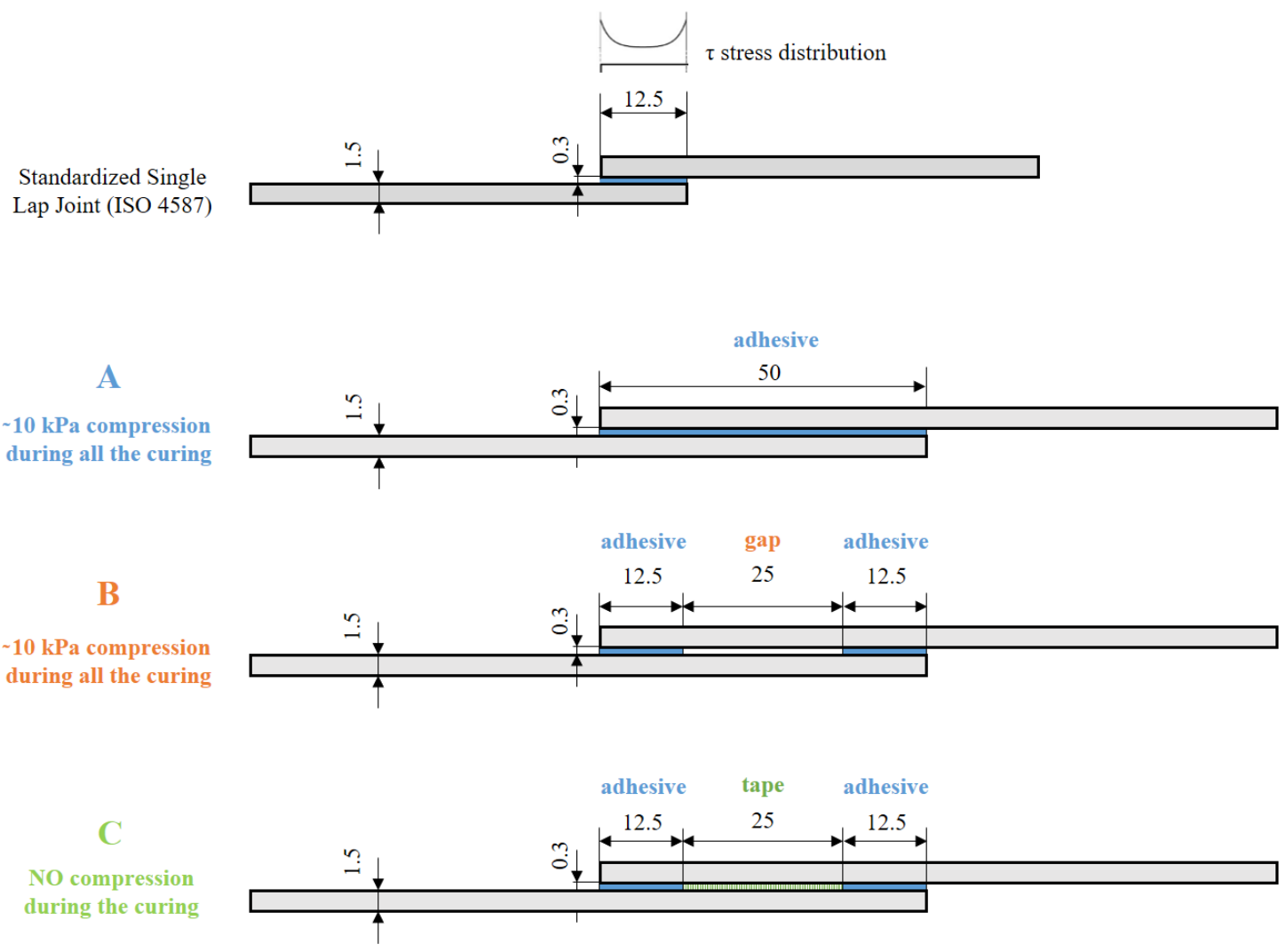

Figure 1. Schematic comparison between the standardized SLJ and the specimens used in this work $(\mathrm{A}, \mathrm{B}, \mathrm{C})$.

As a central gap in the adhesive overlap is supposed to have a minimum effect on the joint strength, as resulting from the literature review, a negligible influence of the presence of the tape upon the joint strength was expected as well, given the very low stiffness of the acrylic foam core of the adhesive tape. Nevertheless, the main innovative feature is that the $\mathrm{C}$ specimen, after a 30 second compression ensured by a clamp, got the minimum handling strength even if the cure of the epoxy adhesive had just started. Then the joint was allowed to achieve full curing, without the application of any additional pressure.

The choice of not applying weights was determined by the aim of demonstrating that the adhesive tape can be used as a substitute of other means usually required to keep 
the joints in the correct position during curing. In facts, while the $\mathrm{C}$ specimen could be handled during curing time without any damage, the integrity of A and B specimens would be highly affected by movements and they needed a jig and weights on top in order to control and preserve the correct positioning of the adherends and the compression state during the whole handling time. In any case, for comparison purposes, tests were conducted on B specimens bonded without weights, identified as BX. A fourth series of specimen, identified as $\mathrm{CT}$, was also manufactured like the $\mathrm{C}$ one, but without any epoxy, in order to evaluate the contribution of the adhesive tape to the total strength of the type $\mathrm{C}$ joint and to evaluate the handling strength of the $\mathrm{C}$ specimens. The adherends of all the specimens were made of a $1.5 \mathrm{~mm}$ thick sheet of galvanized S350 Z275 of minimum 350 MPa yield strength. The interest into the use of galvanized steel stemmed from the need of manufacturing a large structure, for which methods for reducing the handling time are being sought. The width of the specimens was $24.5 \mathrm{~mm}$.

Before bonding, the specimens were cleaned with acetone, then abraded with a grit 60 sandpaper. A second cleaning with acetone after abrasion ensured the complete removal of all particles left by abrasion. To ensure a minimum bondline thickness, the adhesive was mixed with glass microspheres, with a diameter between 250-300 $\mu \mathrm{m}$, and spread on the specimens using a metallic spatula. Figure 2 shows the A, B, C and CT specimens before being assembled. The alignment of the specimen was ensured by the jig shown in Figure 3. The cure was completed in an oven at a temperature between 60 $65^{\circ} \mathrm{C}$ along 3 hours for a fast cure [19]. The same amount of pressure was applied by means of a different number of steel blocks placed on the overlap of the A and B specimens (overlap area of specimen A is two times that of specimens B, therefore two blocks were used). In Figure 3, two A specimens, with two weights each on top, and two B specimens, with one weight each on top, are clearly shown. The weight of the blocks 
divided by the area of the overlap corresponded to a pressure of about $10 \mathrm{kPa}$. The initial pressure required for the activation of the tape was applied to $\mathrm{C}$ specimens for $30 \mathrm{~s}$ by means of a clamp, whereas for the remaining curing time no additional weights were applied. A second series of B specimens, identified as BX, was bonded without weights. The test plan is summarized in Table 3, where the type, the number of specimens and the bonding conditions are reported.

A

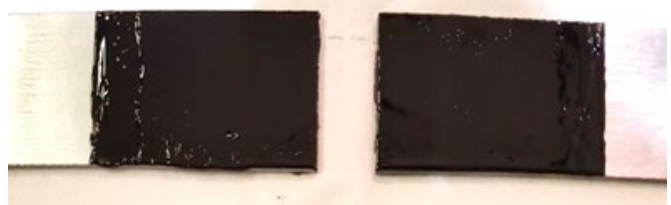

B

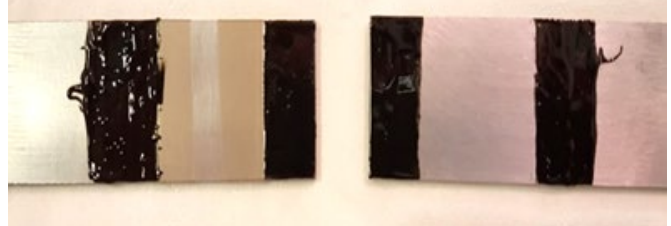

$\mathrm{C}$

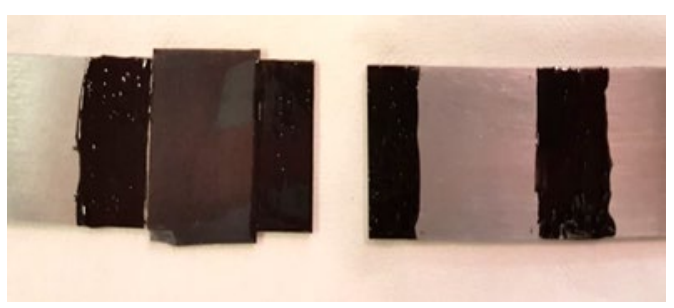

CT

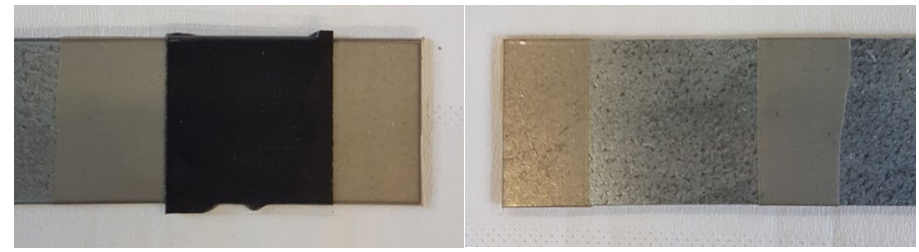

Figure 2. A, B, C and CT specimens during the preparation. In the B specimen, the central gap was guaranteed by a PTFE tape. In the C specimen, the central gap was filled in one of the two adherends by the double-sided pressure-sensitive tape. In the CT specimen, the PTFE tape replaced the epoxy of the $\mathrm{C}$ specimen. 
Table 3. Summary of the test plan

\begin{tabular}{c|c|c}
\hline Specimen type & $\begin{array}{c}\text { Number of } \\
\text { specimens }\end{array}$ & Bonding conditions \\
\hline A & 5 & Weights $(10 \mathrm{kPa})$ \\
\hline B & 5 & Weights $(10 \mathrm{kPa})$ \\
\hline $\mathrm{BX}$ & 5 & No Weights \\
\hline $\mathrm{C}$ & 5 & $\begin{array}{c}\text { No Weights, pressure } \\
\text { activation by clamping }\end{array}$ \\
\hline $\mathrm{CT}$ & 3 & $\begin{array}{c}\text { No Weights, pressure } \\
\text { activation by clamping }\end{array}$ \\
\hline
\end{tabular}

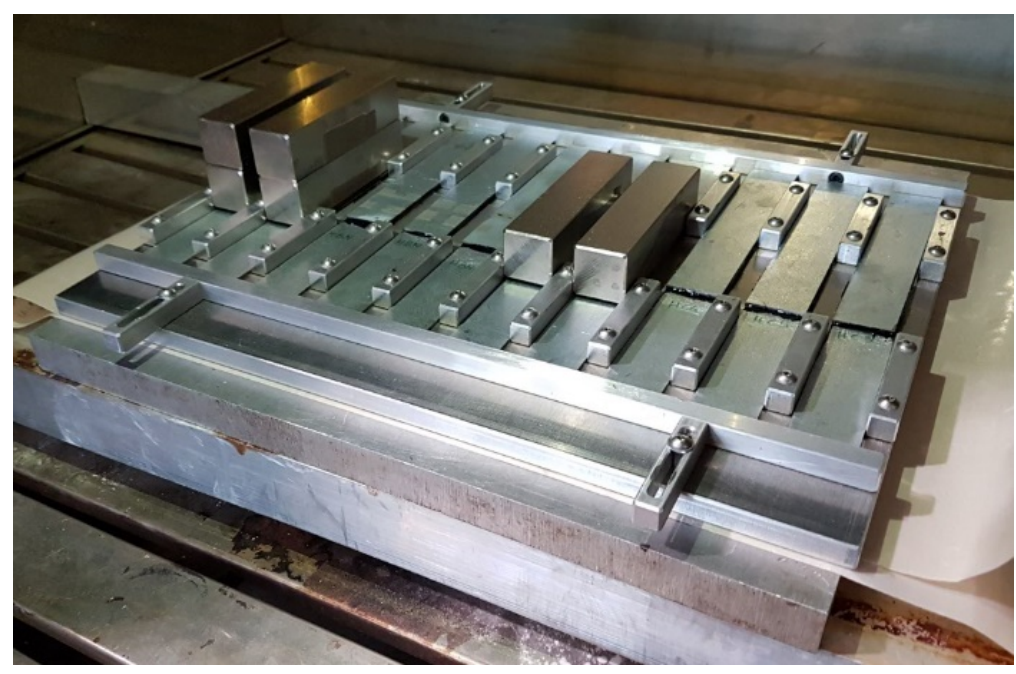

Figure 3. Single-lap joint jig and weights used in this work.

\section{Results and discussion}

The tests were performed using a MTS electro-mechanical testing machine with $150 \mathrm{kN}$ capacity (Figure 4). In order to avoid any sliding between the end tabs of the specimens and the wedges of the grips, hydraulic grips were used. The test speed was 3 $\mathrm{mm} / \mathrm{min}$. The results are reported in Table 4 in terms of maximum load reached at failure. 


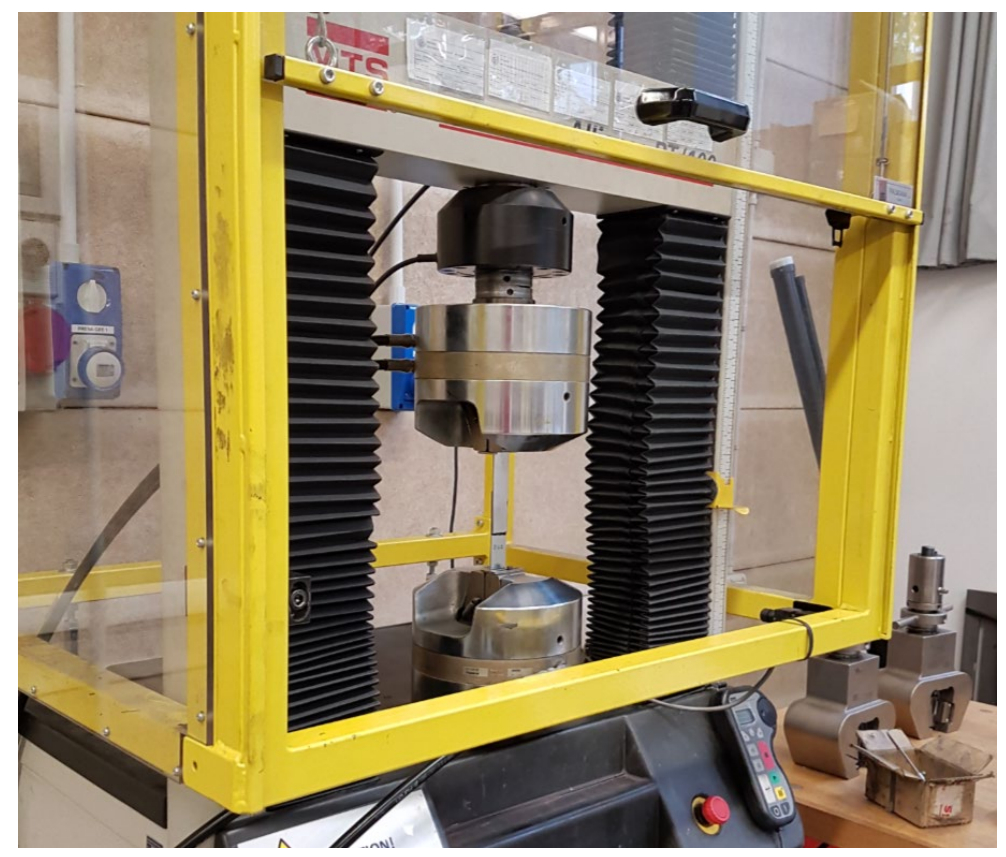

Figure 4. MTS electro-mechanical testing machine with a hybrid joint clamped by the hydraulic grips.

Table 4. Maximum load $(\mathrm{N})$ reached in the experiments

\begin{tabular}{c|cccc|c}
\hline Specimen & A & B & $\begin{array}{c}\text { BX } \\
(\text { w/o } \\
\text { weights })\end{array}$ & C & $\begin{array}{c}\text { CT(tape } \\
\text { only) }\end{array}$ \\
\hline Test 1 & 14.1 & 14.3 & 14.0 & 13.6 & 0.372 \\
Test 2 & 15.1 & 14.3 & 14.3 & 13.3 & 0.373 \\
Test 3 & 15.2 & 14.4 & 13.2 & 14.5 & 0.383 \\
Test 4 & 14.2 & 13.8 & 13.6 & 14.2 & \\
Test 5 & 14.3 & 14.1 & 14.0 & 14.1 & \\
Mean & 14.6 & 14.2 & 13.8 & 13.9 & 0.376 \\
$2 \sigma$ variance & 1.0 & 0.5 & 0.9 & 0.9 & 0.012 \\
\hline
\end{tabular}

Figure 5 shows the results in term of average values of maximum load reached during the tests. The error bars indicate the $\pm 2 \sigma$ variance. The difference between these three types of joints is negligible. The B specimens achieved a maximum load capacity which was only about $3 \%$ less than that of the A specimens, confirming the 
insensitiveness of the strength of the SLJs upon the presence of a gap, presumably due to the similar peak stresses in the adhesive overlap, as discussed in [19]. The C specimens showed a reduction of strength of less than 5\% compared to the A specimens. The mechanical characterization showed that $\mathrm{B}$ and $\mathrm{C}$ specimens are clearly superior to $\mathrm{A}$ ones in terms of reduction of the amount of adhesive used, since the results showed that almost the same strength was achieved with the three types of joints. However, the $\mathrm{C}$ specimen had the great advantage of not having to be constrained in the jig during curing and the tape provided sufficient and instantaneous handling strength for these small size specimens, which could be displaced from the clamp to the oven, without affecting their strength. BX specimens (B specimens bonded without weight) performed like C specimens, thus indicating a moderate effect of the bonding pressure of $10 \mathrm{kPa}$, corresponding to the application of the weights.

The results of the tests on CT specimens (C specimens bonded only with tape) allowed for estimating the handling strength that was achieved almost instantaneously after closing the joint of the $\mathrm{C}$ specimens (where also structural adhesive is present). In fact, the structural adhesive cannot contribute to the strength right after bonding, due to the very long open time of the $7260 \mathrm{~B} / \mathrm{A}$ NS adhesive, whereas the pressure-sensitive tape is activated almost instantaneously. For the same reason, strength of A and B specimens is null right after bonding and handling strength is achieved in about 14 hours at $23^{\circ} \mathrm{C}$ [20]. The estimated instantaneous handling of the $\mathrm{C}$ specimens strength should correspond to the same ultimate load of $376 \mathrm{~N}$ of the CT specimen, which largely exceeds the weight of the specimen but should also allow for handling larger parts bonded with this type of joint. 


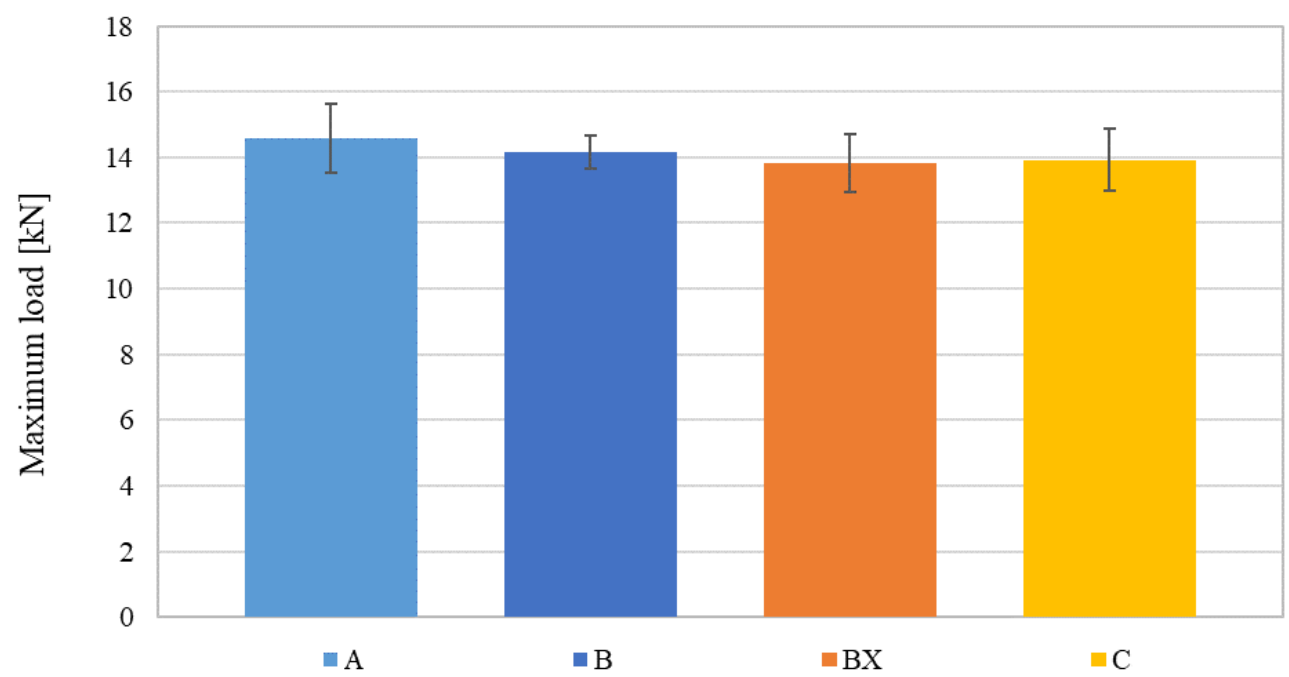

Figure 5. Maximum reached load for each type of specimen.

Values of the average shear stress at failure were evaluated dividing the average of the maximum force by the area of the bondline. In the case of $\mathrm{C}$ specimens, the area is evaluated with reference of the portion of the overlap bonded with the structural adhesive, neglecting the contribution of the tape, due to the very low stiffness of its acrylic foam core. Values are reported in Table 5.

Table 5. Bonded surface area and average shear stress (MPa) reached in the experiments

\begin{tabular}{c|cccc}
\hline Specimen & A & B & $\begin{array}{c}\text { BX } \\
(\mathrm{w} / \mathrm{o} \\
\text { weights })\end{array}$ & $\mathrm{C}$ \\
\hline $\begin{array}{c}\text { Bonding } \\
\text { pressure (kPa) } \\
\text { during curing }\end{array}$ & 10 & 10 & 0 & 0 \\
\hline $\begin{array}{c}\text { Nominal } \\
\text { bonded surface } \\
\text { area }\left(\mathrm{mm}^{2}\right)\end{array}$ & 1225 & 612.5 & 612.5 & 612.5 \\
\hline $\begin{array}{c}\text { Average shear } \\
\text { stress }(\mathrm{MPa})\end{array}$ & 11.9 & 23.1 & 22.6 & 22.7 \\
$2 \sigma$ variance & 0.9 & 0.8 & 1.4 & 1.5 \\
\hline
\end{tabular}

Figure 6 shows the load vs displacement curves of the A, B, BX and C tests. Yielding of the adherends took place in all tests before failure of the adhesive. The curves 
show that all the elongations at failure were comprised between 3-5 $\mathrm{mm}$, except for two A specimens with a larger elongation (between 6-7 $\mathrm{mm}$ ) and for two $\mathrm{C}$ specimens, with a shorter elongation (between 1-2 $\mathrm{mm}$ ). Values of the maximum displacements are reported in Table 6 .

It appears that a larger quantity of epoxy adhesive in the overlap produces a higher average elongation, since B and C specimens respectively displayed a $24 \%$ and $39 \%$ lower displacement at failure compared to the A ones. The $\mathrm{C}$ specimens showed also a larger scatter of the displacement data. Concluding, in this SLJ configuration, the specimens with pressure-sensitive tape and less epoxy displayed a reduction of the elongation, although the load capacity of the joint was preserved.

The lower displacement at failure of $\mathrm{C}$ specimens could represent a negative aspect. Another negative point of $\mathrm{C}$ specimens is the difficulty of repositioning the adherends in case of erroneous alignment. Once the tape has been activated, to open the joint the tape needs being degraded at very high temperatures and then recovery of surfaces would require cumbersome treatments.

Table 6. Maximum crosshead displacement ( $\mathrm{mm})$ reached in the experimental campaign.

\begin{tabular}{c|cccc}
\hline Specimen & A & B & $\begin{array}{r}\text { BX (w/o } \\
\text { weights })\end{array}$ & C \\
\hline Test 1 & 4.2 & 4.0 & 4.3 & 1.7 \\
Test 2 & 6.4 & 4.7 & 4.3 & 1.3 \\
Test 3 & 6.7 & 4.3 & 1.1 & 4.9 \\
Test 4 & 4.4 & 3.3 & 2.0 & 4.3 \\
Test 5 & 4.2 & 3.3 & 3.7 & 3.6 \\
Mean & 5.2 & 3.9 & 3.1 & 3.2 \\
$2 \sigma$ variance & 2.6 & 1.3 & 3.0 & 3.1 \\
\hline
\end{tabular}




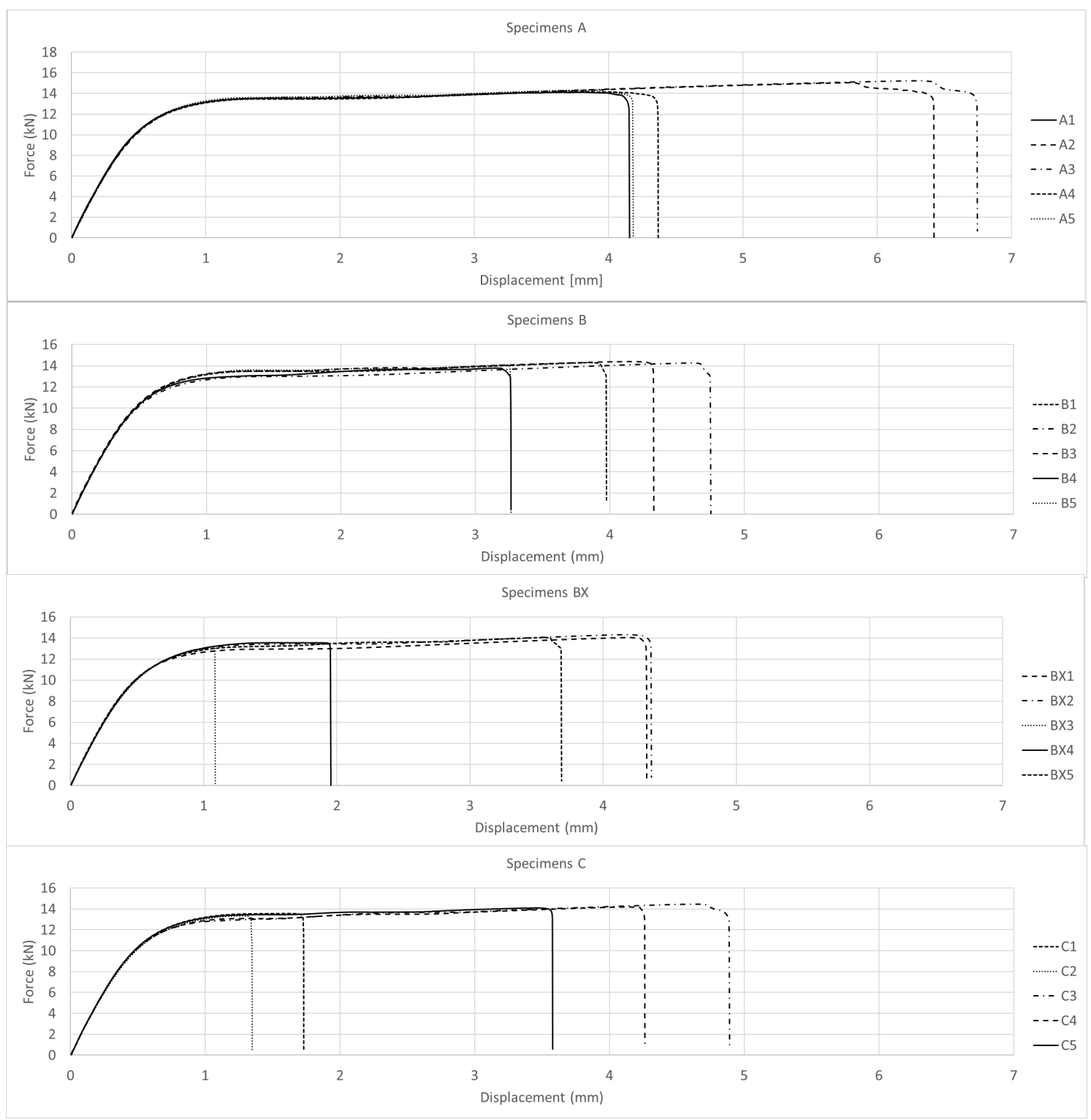

Figure 6. Experimental load vs crosshead displacement curves.

In spite of abrasion and careful cleaning, the failure of the adhesive in the adhesively bonded specimens was almost completely adhesive in all the cases, as shown in Figure 7. In the case of $\mathrm{C}$ and $\mathrm{CT}$ specimens (Figure 10), the double-sided pressuresensitive tape always failed cohesively. However, reaching the best cohesive performance of the adhesive was not the aim of this work, being the main goal the comparative analysis of the performances of the different joints, to test the capability of a pressure-sensitive tape to provide immediate handling strength, without affecting the strength of the joint. 
Future tests will be conducted in order to improve the performance of the joints, e.g. by proper surface activation treatments [23] and similar tests, also with other adhesives, are required before demonstrating that the proposed method can be adopted as an industrial solution.
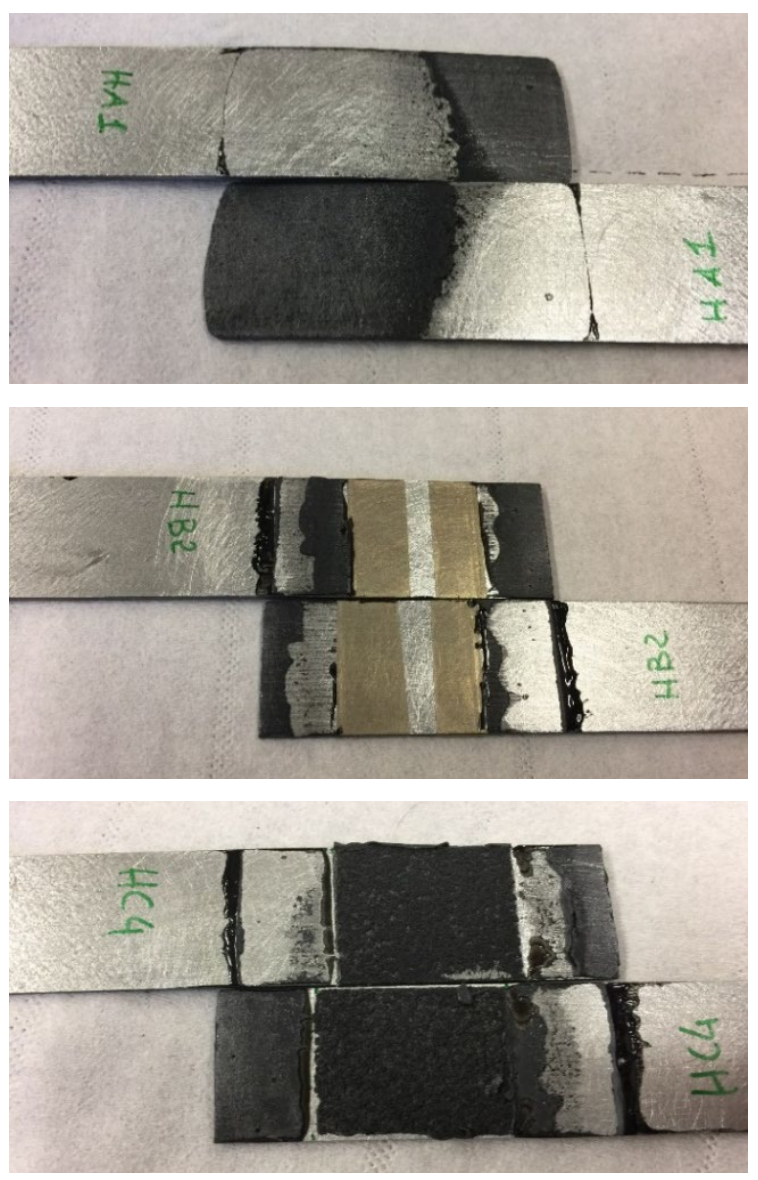

Figure 7. Failure surfaces of A (top), B (middle) and C (bottom) specimens.

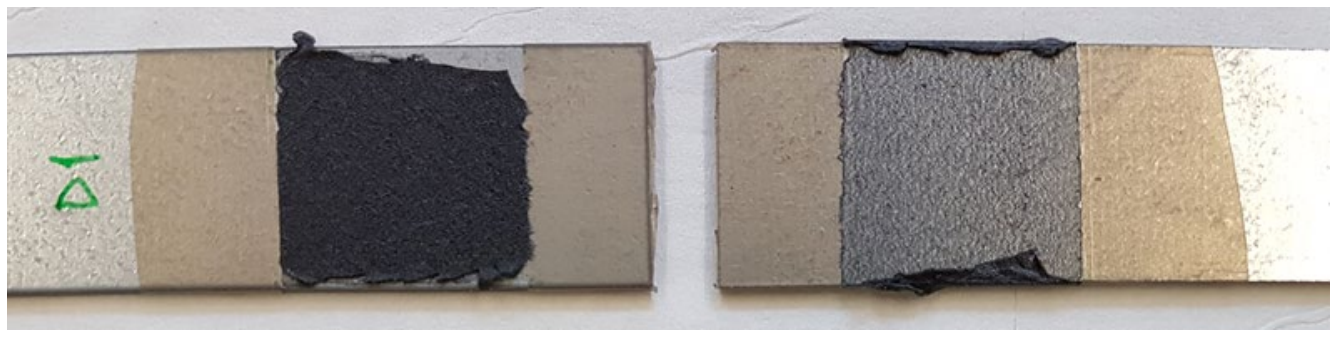

Figure 10. Failure surface of a CT specimen

Nevertheless, the tests presented herein confirm that the presence of a gap does not alter the strength of a SLJ and that the gap can be used to position a pressure-sensitive 
tape to reach almost immediate handling strength without affecting significantly the strength of the joint. Moreover, the tape could also be used to control the thickness of the adhesive layer, thus avoiding other methods, like inclusion of glass spheres into the structural adhesive.

\section{Conclusions}

In this paper, a possible method for achieving almost immediate handling strength of a SLJ bonded with structural epoxy adhesive is investigated. The method consists of exploiting the low sensitivity of the strength of SLJ upon the presence of a gap in the bondline, by inserting a double-sided pressure-sensitive tape into the gap.

To assess the sensitivity of the strength of the joint upon the presence of a gap, tests were first conducted on a single-lap joint made only by adhesive (A) and a singlelap joint with a central gap (B). Then, a third specimen (C) was manufactured, inserting a segment of pressure sensitive tape, filling completely the gap of specimen B.

The results showed that all specimen types had a very similar strength, but elongation at failure diminished with the use of the tape. The main advantage of using the tape consists of reducing the handling time to an almost negligible duration, i.e. that of the application of the activation pressure. Conversely, A and B specimens require a certain time to reach handling time (between 14 and 16 hours for curing at room temperature [19]), whereas the C specimen was almost instantaneously ready for handling.

These preliminary results seem to indicate that the handling time of an adhesive structural joint can be reduced to a few seconds by the combined use of structural 
adhesives and pressure-sensitive tapes. This is possible only if activation pressure can be applied and if measures are taken to ensure that no correction of the alignment is needed after activation of the tape. Tests on specimens bonded with the pressure-sensitive tape allowed to assess the intrinsic strength of the joint immediately after the application of the activating pressure, when the structural adhesive is not capable of bearing any load.

The strength is largely sufficient to handle the specimen, however future investigations should focus on the limits of application of this solution to real structures, where the handling strength should correspond to the possibility of displacing them as soon as possible after bonding, e.g. for the following stages of assembly. In this case, selfweight is likely to become a non-negligible source of stress in the bondline, compared with small size specimens. Nevertheless, we believe that these preliminary results are encouraging and that the proposed solution might allow for considerable cost reduction, should the applicability to real, larger structures be proven.

\section{References}

[1] Habenicht, G., Applied Adhesive bonding: A Practical Guide for Flawless Results, (WILEY-VCH Verlag GmbH \& Co. KGaA, Weinheim, 2009). 1st ed., Chap. 1-3, pp. 1-3, 13-18.

[2] Adams, R.D., Wake, W.C., Structural Adhesive Joints in Engineering, (Elsevier Applied Science Publishers LTD, London and New York, 1984). 1st ed., Chap. 8, pp. 271-282.

[3] Brockmann, W., Geiss, P.L., Vogt, D., PSTC TECH 27. Assessment and Prediction of Long-Term Properties of Pressure Sensitive Tapes in Semi-Structural Applications (2004). 
[4] Ciccotti, M., Giorgini, B., Vallet, D., Barquins, M., Int. J. Adhes. Adhes. 24, 143$151(2004)$.

[5] McGuiggan, P.M., Chiche, A., Filliben, J.J., Yarusso, D.J, Int. J. Adhes. Adhes. 28, $185-191(2008)$.

[6] Kowalczyk, A., Kowalczyk, K., Int. J. Adhes. Adhes. 67, 44-48 (2016).

[7] da Silva, L.F.M., Pirondi, A., Öchsner, A., Advanced Structural Material Vol.6 Hybrid Adhesive Joints, (Springer-Verlag Berlin Heidelberg, London and New York, 2011). 1st ed.

[8] Gómez, S., Oñoro, J., Pecharromán, J., Int. J. Adhes. Adhes. 27, 263-267 (2007).

[9] Sadowski, T., Kneć, M., Golewski, P., Int. J. Adhes. Adhes. 30, 338-346 (2010).

[10] Campilho R.D.S.G., Pinto, A.M.G., Banea, M.D., da Silva, L.F.M., Int. J. Adhes. Adhes. 37, 86-95 (2012).

[11] Bartczak, B., Mucha, J., Trzepieciński, T., Int. J. Adhes. Adhes. 45, 42-52 (2013).

[12] da Silva, L.F.M., Lopes, M.J.C.Q., Int. J. Adhes. Adhes. 29, 509-514 (2009).

[13] Geiss P.L., Koetter M.P., Presser M., Raudonat D., PSTC TECH 33. Hybrid Joining with Pressure Sensitive Adhesives (2010).

[14] Saldanha, D.F.S., Canto, C., da Silva, L.F.M., Carbas, R.J.C., Chaves, F.J.P., Nomura, K., Ueda, T., Int. J. Adhes. Adhes. 47, 91-98 (2013).

[15] Olia, M., Rossettos, J.N., Int. J. Solids Struct. 33, 2681-2693 (1996).

[16] Lang, T.P., Mallick, P.K., Int. J. Adhes. Adhes. 19, 257-271 (1999). 
[17] de Moura, M.F.S.F., Daniaud, R., Magalhães, A.G., Int. J. Adhes. Adhes. 26, 464$473(2006)$.

[18] Engerer, J. D., Sancaktar E., Int. J. Adhes Adhes 31, 373-379 (2011)

[19] 3M Scotch-Weld ${ }^{\mathrm{TM}}$ Epoxy Adhesive 7260 B/A, Product Data Sheet (2003).

[20] 3M Scotch-Weld ${ }^{\mathrm{TM}}$ Epoxy Adhesive 7260 B/A, Bullettin Technique BT 0905-0203 (in French) (2003).

[21] 3M VHB ${ }^{\text {TM }}$ Tape 5906, 5907, 5908, 5909, Technical Data (2014).

[22] International Standard ISO 4587, Adhesives - Determination of tensile lap-shear strength of rigid-to-rigid bonded assemblies, 3rd edition (2003).

[23] Critchlow G, Bedwell KH, Cottam CA. Transactions of the Institute of Metal Finishing 76(5):203-206 (1998) 